\title{
Unsuspected Ganglioneuroma of the Choroid Diagnosed after Enucleation
}

\author{
Michael Mbagwu $^{a} \quad$ Bahram Rahmani $^{\mathrm{a}} \quad$ Arth Srivastava $^{\mathrm{b}}$ Delilah Burrowes ${ }^{\mathrm{c}}$ \\ Paul J. Bryar ${ }^{\mathrm{a}}$ \\ Departments of a Ophthalmology, ${ }^{b}$ Neurology and ${ }^{c}$ Radiology, Northwestern University Feinberg School of \\ Medicine, Chicago, III., USA
}

\section{Key Words}

Ganglioneuroma · Orbital tumor · Neurofibromatosis

type $1 \cdot$ von Recklinghausen disease $\cdot$ Orbital imaging

\begin{abstract}
We report a case of an unsuspected ganglioneuroma of the choroid in a patient with neurofibromatosis type 1. A 5-yearold girl presented from an outside institution with right proptosis and glaucoma since birth. Magnetic resonance imaging was obtained and showed a cavernous sinus mass extending into the right orbit and multiple orbital lesions. Additionally, increased signal in the posterior globe of the right eye was noted, but its etiology was unclear at the time. She was lost to follow-up for 3 years and later returned with a blind painful eye. Enucleation was performed, and histopathology was significant for diffuse choroidal ganglioneuroma and advanced glaucoma. We report the atypical history, examination findings, and histopathology to support the diagnosis.

(c) 2015 S. Karger AG, Basel
\end{abstract}

\section{Case Report}

A 5-year-old girl presented at Lurie Children's Hospital with right eye discomfort, right proptosis, and glaucoma. She had a history of neurofibromatosis type 1 (NF1), right proptosis and glaucoma since birth, which were treated at an outside institution. Initial exam revealed counting fingers vision in the right eye and 20/40 vision in the left. Right proptosis and ptosis were present (fig. 1). The right cornea was cloudy and had an enlarged diameter. Intraocular pressures were $40 \mathrm{~mm} \mathrm{Hg}$ in the right and $20 \mathrm{~mm} \mathrm{Hg}$ in the left. There was no view to the fundus in the right eye due to the corneal opacity. The left fundus was unremarkable. Ocular medications included latanoprost, brinzolamide, and carteolol. Magnetic resonance imaging (MRI) revealed multiple orbital lesions and a cavernous sinus mass extending into the right orbit, consistent with neurofibroma with increased signal in the posterior globe of the right eye. Additionally, there was a dysplastic sphenoid wing (fig. 2).

The patient was lost to follow-up after the MRI was obtained. Over the next 3 years, the patient was seen at several different institutions with uncontrolled glaucoma. She returned at the age of 8 years with a blind painful eye, and enucleation was recommended and subsequently performed. Gross examination of the globe revealed an axial length of $28 \mathrm{~mm}$ and an enlarged corneal diameter of $16 \mathrm{~mm}$. Microscopic examination revealed loss of corneal stromal clefting and an attenuated endothelium, consistent with her history of corneal opacity and glaucoma. Advanced cupping of the optic nerve and attenuation of the ganglion cell and nerve fiber

\section{KARGER}

E-Mail karger@karger.com

www.karger.com/oop
C 2015 S. Karger AG, Base

2296-4681/15/0021-0048\$39.50/0
Michael Mbagwu

Institute of Public Health and Medicine

Northwestern University Feinberg School of Medicine

633 N. St. Clair Street, 20th Floor, Chicago, IL 60611 (USA)

E-Mail Michael-Mbagwu@ Northwestern.edu 


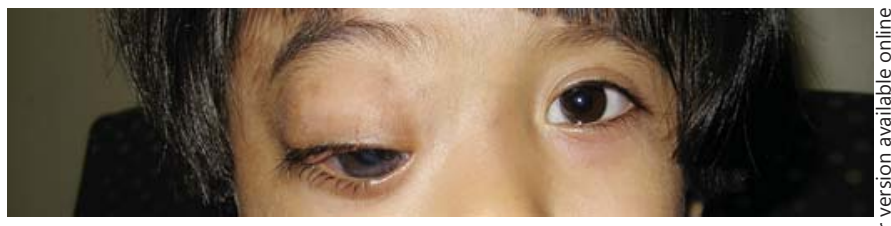

Fig. 1. Clinical photograph.

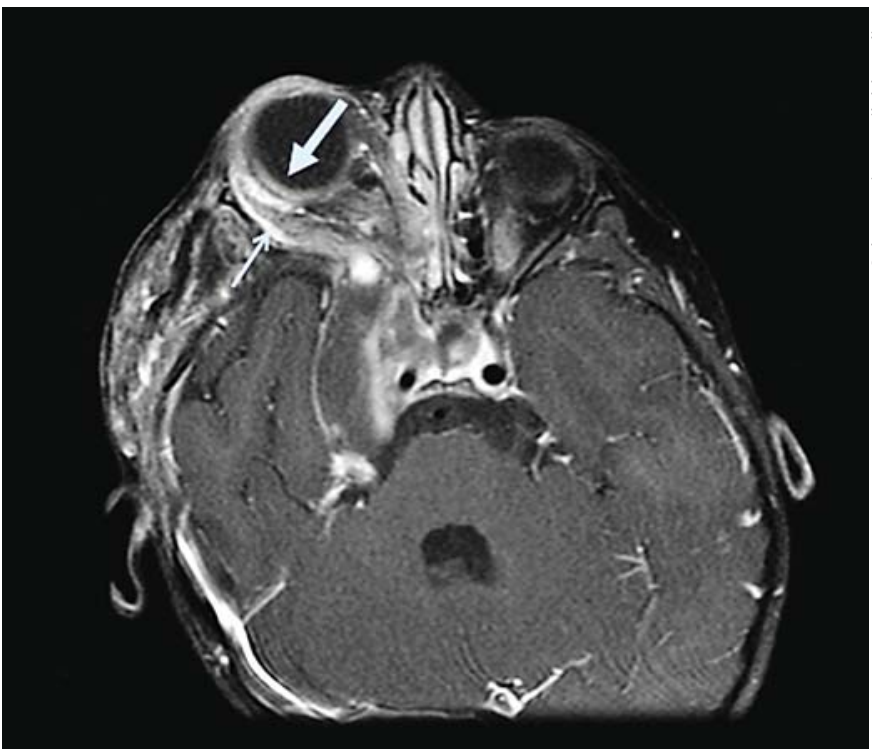

Fig. 2. MRI: T1 fat-saturated post-gadolinium image showing a cavernous sinus mass extending into the right orbit and multiple orbital lesions consistent with neurofibroma (smaller arrow). There was increased signal in the posterior globe of the right eye (larger arrow).

layers were consistent with glaucoma. The choroid was mildly thickened. Approximately $50 \%$ of the choroid was replaced with tumor containing cells with spindle shaped nuclei and scattered ganglion cells (fig. 3a, b). The final histopathologic diagnoses were advanced glaucoma and diffuse choroidal ganglioneuroma (GN).

\section{Discussion}

NF1 (also known as von Recklinghausen disease) is a disorder that is generally inherited, but can also come as a result of novel mutations, and has an incidence of 1 : 2,600-3,000 [1]. NF1 manifests clinically in a variety of organ systems, including cutaneous (i.e. dermal neural fibromas, café au lait spots, or freckling in non-sun exposed areas), musculoskeletal (i.e. skeletal dysplasias, scoliosis, osteoporosis), and ocular (i.e. Lisch nodules on

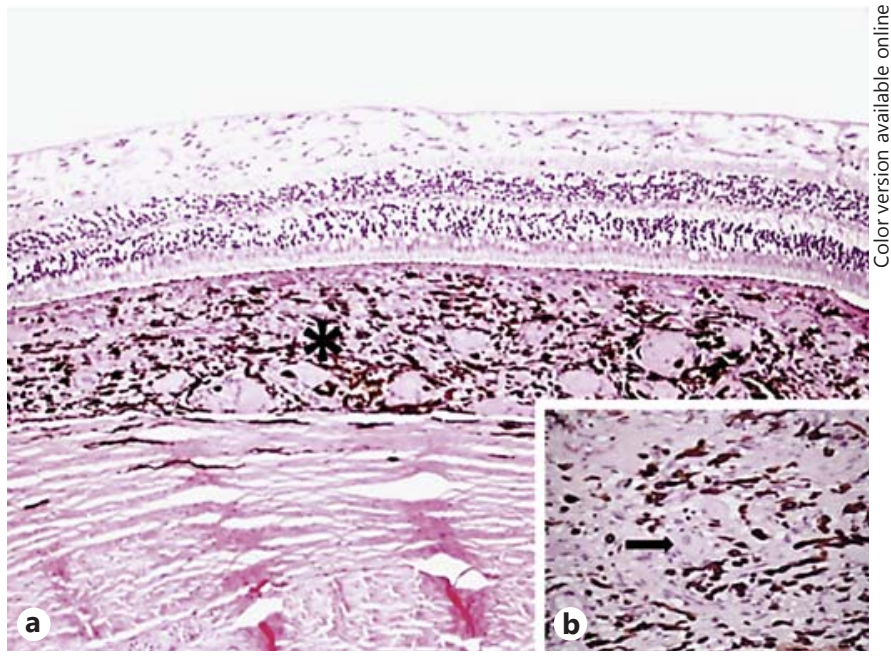

Fig. 3. a, b Histopathology reveals a thickened choroid (a, asterisk) with Schwann cells with spindle-shaped nuclei and scattered ganglion cells (b, arrow). HE. $\times 10$ lens $(\times 40$ inset $)$.

Table 1. Imaging modalities and findings from GN case reports

\begin{tabular}{lll}
\hline $\begin{array}{l}\text { Case No. } \\
\text { [ref. }\end{array}$ & $\begin{array}{l}\text { Imaging } \\
\text { modality used }\end{array}$ & Findings \\
\hline $1[5]$ & MRI & $\begin{array}{l}\text { Heterogeneous orbital mass; } \\
\text { diffusely thickened choroid }\end{array}$ \\
\hline $2[6]$ & $\begin{array}{l}\text { MRI and } \\
\text { ultrasound }\end{array}$ & $\begin{array}{l}\text { MRI: soft tissue tumor; diffuse } \\
\text { choroidal thickening } \\
\text { Ultrasound: vitreous hemorrhage } \\
\text { and choroidal thickening }\end{array}$ \\
\hline $3[7]$ & None & N/A \\
\hline $4[8]$ & MRI & $\begin{array}{l}\text { Vitreous hemorrhage; choroidal } \\
\text { tumor }\end{array}$ \\
\hline $5[9]$ & CT & $\begin{array}{l}\text { Enlarged left eye; hypoplastic } \\
\text { greater wing of the sphenoid }\end{array}$ \\
\hline $6[10]$ & None & N/A \\
\hline
\end{tabular}

$\mathrm{CT}=$ Computed tomography; $\mathrm{N} / \mathrm{A}=$ not available.

the iris, optic nerve gliomas, and retinal astrocytic hamartomas) [1]. Much less common is the appearance of GN.

GNs are benign tumors that arise from primordial neural crest cells and are comprised of ganglion cells, Schwann cells, and fibrous tissue. These rare tumors may either arise de novo or may differentiate from a neuroblastoma or ganglioneuroblastoma [2]. GNs are usually 
localized to the posterior mediastinum or retroperitoneum and slightly less frequently to the adrenal medulla. In more advanced stages of the tumor, GNs have been reported in the orbit, vertebral spines, liver, and lung, but are extremely rare in the choroid as presented here $[3,4]$.

Reports on choroidal GN with NF1 have been scarce in the literature, with a PubMed search retrieving only 6 published case reports [5-10]. In all cases, the GN was not suspected clinically. In 4 of the cases, MRI, computed tomography or ultrasound showed some abnormality (table 1). In the remaining cases, imaging either did not reveal a choroidal abnormality or was not preformed (table 1). Histopathological examination confirmed GN of the choroid, although this was not on the differential diagnosis and was therefore clinically unsuspected. In our case, imaging revealed an orbital tumor and an abnormal signal enhancement in the posterior globe, but no discrete intraocular tumor was appreciated. In all of the cases, final diagnosis was not made until after histopathologic examination of the globe. In 1 of the 6 cases, the diagnosis of NF1 was not made until after enucleation and discovery.

Even in the absence of GNs, choroidal abnormalities have been detected in patients with NF1 [11]. In a small study of 17 patients with NF1, bright multiple patchy regions were found in all affected patients using infrared monochromatic light examination by confocal scanning laser ophthalmoscopy [11]. These abnormalities were not previously detected during conventional examination or fluorescein angiography. A follow-up study showed that these abnormalities increased with the age of the patient and had a primary distribution in the vascular arcade region [12]. Histopathological examination has not been reported on any patients with these abnormalities.

In summary, $\mathrm{GN}$ is a rare tumor of the choroid, usually seen in patients with NF1. Index of suspicion should be increased with abnormal choroidal appearance on exam and/or radiographic findings of intraocular mass, diffuse choroidal thickening, or abnormal signal strength.

\section{Statement of Ethics}

All subjects described in this paper were treated in an ethical manner. Additionally, subjects were given the appropriate consent/treated in an ethical manner consistent with the requirements by the Northwestern University Institutional Review Board Office in Chicago, Ill., USA.

\section{Disclosure Statement}

None of the authors have any proprietary interests, financial competing interests, or conflicts of interest related to this submission.

\section{References}

$\checkmark 1$ Goldgar C: Neurofibromatosis, type 1 (von Recklinghausen disease). JAAPA 2011;24:7576,78 .

2 Geoerger B, et al: Metabolic activity and clinical features of primary ganglioneuromas. Cancer 2001;91:1905-1913.

- 3 Hayes FA, Green AA, Rao BN: Clinical manifestations of ganglioneuroma. Cancer 1989; 63:1211-1214.

4 Spencer W: Ophthalmic Pathology: An Atlas and Textbook, ed 4. San Francisco, Saunders, 1996, vol 3

5 Goyal S, et al: Choroidal ganglioneuroma and orbital plexiform neurofibroma presenting as buphthalmos in an infant with neurofibroma- tosis type 1. Ophthal Plast Reconstr Surg 2014, Epub ahead of print.

-6 Yazici B, Ozgun G, Adim SB: Choroidal ganglioneuroma in a patient with orbitopalpebral neurofibromatosis. Ophthal Plast Reconstr Surg 2014;30:e140-e142.

7 Ozgun G, et al: Co-occurrence of choroidal pigmented ganglioneuroma and plexiform neurofibroma in a patient with neurofibromatosis 1. Kaohsiung J Med Sci 2014;30:215216.

8 Ishijima K, et al: Intraocular neovascularization associated with choroidal ganglioneuro$\mathrm{ma}$ in neurofibromatosis type 1 . Eur J Ophthalmol 2011;21:837-840.
Shome D, Vemuganti GK, Honavar SG: Choroidal ganglioneuroma in a patient with neurofibromatosis type 1: a case report. Eye (Lond) 2006;20:1450-1451.

10 Woog JJ, et al: Choroidal ganglioneuroma in neurofibromatosis. Graefes Arch Clin Exp Ophthalmol 1983;220:25-31.

11 Yasunari T, et al: Frequency of choroidal abnormalities in neurofibromatosis type 1. Lancet 2000;356:988-992.

12 Nakakura S, et al: Quantification and anatomic distribution of choroidal abnormalities in patients with type I neurofibromatosis. Graefes Arch Clin Exp Ophthalmol 2005;243:980984 